\section{ICONOS DE LA LEY, \\ LITERATURAS DEL DESASTRE. \\ LA FIGURA DE MOISÉS \\ EN LA OBRA DE SCHÖNBERG \\ Y THOMAS MANN}

\author{
Fernando Bayón \\ Instituto de filosofía-CCHS/CSIC \\ C/ Albasanz, 26-28 Madrid 20037 \\ fernando.bayon@cchs.csic.es
}

\section{ICONS OF THE LAW, LITERATURES OF DISASTER. THE FIGURE OF MOSES IN ARNOLD SCHÖNBERG AND THOMAS MANN}

\begin{abstract}
This essay is an attempt of interpretation of the figure of Moses as elaborated in Thomas Mann's short story "The Law", and Arnold Schönberg's opera "Moses und Aron". In the case Schönberg's, the dramatical recuperation of the jewish legislator-and his brother- results in an attempt of responding to the crisis of the Republic of Weimar from his "exile" in Berlin (1924-1933). Thomas Mann, for his part, came back to the fictional figure of Moses once living in his californian exile (1943), and used this mythos as a means of responding to Hitler's dictatorship. The text arises why in historical situations of a very serious gravity, such a great artists like Mann or Schönberg decide to revert to narrate the mosaic mythos. We are specially concerned by a problem of major ethical and political implications: What are the forces needed to achieve a common ethos? And what are the violences avoided by this search for a moral link protagonized by an oppressed people?
\end{abstract}

KEY WORDS: Thomas Mann; Arnold Schönberg; Moses; monotheism; law; decalogue; exodus; pluralism; exile of the II World War; Republic of Weimar; opera; dodecaphonism.

"Seine Geburt war unordentlich, darum liebte er leidenschaftlich Ordnung, das Unverbrüchliche, Gebot und Verbot." Thomas Mann, Das Gesetz

\section{El mito de Moisés y el eXILIO alemÁN}

¿Por qué volver a narrar el mito de Moisés precisamente entonces? ¿Por qué hacer memoria de lo que Jan Assmann denomina "las consecuencias psicohistóricas del monoteis-
RESUMEN: Este texto pretende acercarse a la figura de Moisés tal como se elabora en el relato "La ley" de Thomas Mann (1943), y la ópera "Moisés y Aarón" de Arnold Schönberg (1932). En el caso de Schönberg, la recuperación del legislador judio resulta en un esfuerzo por responder a la crisis de la república de Weimar desde su exilio berlinés. Thomas Mann, por su parte, vuelve tras el mito de Moisés desde su exilio estadounidense, como respuesta a la dictadura nacionalsocialista. El ensayo se plantea por qué en situaciones históricas de una gravedad tan crítica el arte decide volver a narrar el mito mosaico. Especialmente nos interesa estudiar la actualidad que le conceden tanto Mann como Schönberg al problema y el método de la imposición del monoteísmo a través de la fuerza moralizadora de la Ley, en competición con el pluralismo de dioses, imágenes y normas del pueblo. Intentaremos mostrar cómo ambos artistas intentan responder a un problema de gran calado ético en la época: cuáles son las violencias necesarias para y cuáles las violencias evitadas por la búsqueda política de un ethos común para un pueblo oprimido.

PALABRAS CLAVE: Thomas Mann; Arnold Schönberg; Moisés; monoteísmo; ley; decálogo; éxodo; pluralismo; exilio en la Segunda Guerra Mundial; república de Weimar; dodecafonismo.

mo" en las fechas de la debacle weimariana o bien desde el largo exilio provocado por el III Reich? Fueron muchos los que volvieron la vista hacia Moisés: Freud, Schönberg, Thomas Mann, entre ellos. El mito de Moisés, como dice Assman, "traza una frontera y concierne a una distinción: la distinción entre Egipto e Israel, entre la vieja y la nueva relación con el mundo, entre los dioses ajenos y el dios único y verdadero, entre verdadero y falso en la religión y, en última instancia, entre dios y mundo" (Assmann, 2006, 137). Si el monoteísmo fue históricamente producto de un éxodo, de una revolución, de una conversión, de una 
innovación radical, el recuerdo de su gran legislador en la esfera judeocristiana parece que fue un asunto vital para muchos de los artistas que quisieron responder de la manera más contundente a la crisis de la república de Weimar y a la dictadura en que ésta se desfondó.

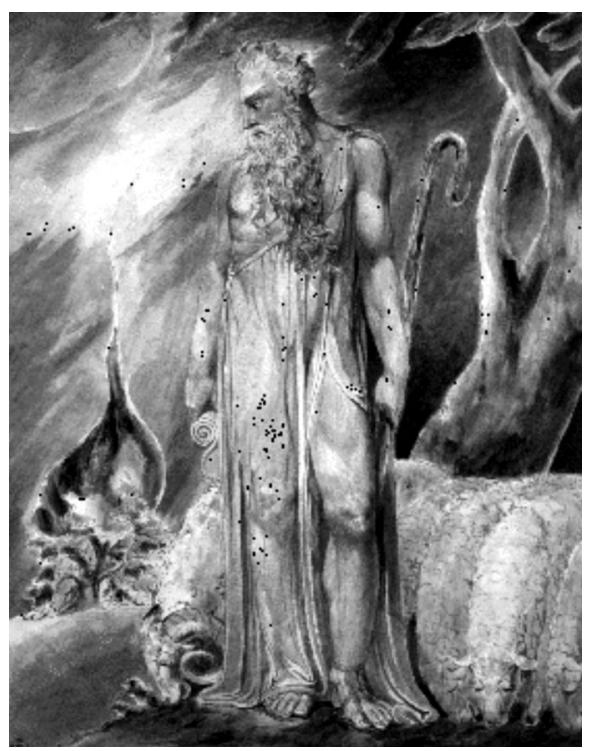

Ilustración 1. William Blake, "Moisés y la zarza".

La experiencia de la catástrofe supuso la recuperación de la distinción mosaica. Cuando la decencia y la dignidad humanas son atacadas de un modo tan peligroso que su reivindicación deja de causar vergüenza a la más sofisticada intelligentsia, que ya no puede ver en ellas ridículas beaterías sin futuro, vuelve la fábula mosaica: ¿por qué la "civilización" europea -y su arte- se agarra en momentos de catástrofe a una (nueva) sublimación de Moisés?

[...] ya no podemos apelar a verdades "absolutas", sino sólo a verdades "que sirven a la vida" que hay que negociar una y otra vez. La distinción mosaica, como Freud nos ha enseñado, no sólo representa trauma, represión y neurosis, sino también un "progreso en la espiritualidad" al que -por muy caro que tengamos que pagar por él- no hemos de volver a renunciar. Deberemos aferrarnos a la distinción entre verdadero y falso, a los conceptos claros de lo que percibimos como incompatible con nuestras convicciones, si es que tales convicciones han de tener alguna fuerza y profundidad. Con la salvedad de que ya no podremos fundar esta distinción en una revelación fijada por escrito de una vez por todas. (Assmann, 2006, 138)

La república de Weimar se resuelve en un exilio gigantesco (Pérez, 2008): y han sido muchos e intensos los debates acerca de cuáles fueron los límites y cuáles los fundamentos de esa nueva plausibilidad adquirida por el mito de Moisés durante el exilio alemán de 1933-1945. "Se requiere evidentemente -dice Karl-Josef Kuschel en diálogo crítico con Assmann- de una experiencia de ruptura de la civilización para que los hombres estén dispuestos, sin ninguna sobrecomplejidad intelectual o cinismo menospreciador del hombre, a comprometerse por un ethos común" (Assmann, 2006, 210). Sin embargo, los estilos con que se imagina y vindica ese ethos común, esa obligatoriedad con que se quiere contestar a la época de la denigración hitleriana de la ética, son bastante diferentes en Schönberg y en Thomas Mann. Por más que ambos coincidan en alargar la vida de Moisés volviéndolo a narrar...

Las afinidades electivas entre Arnold Schönberg y Thomas Mann -quienes en lo personal habrian de mantener una eterna disputa basada en una reciproca inmodestia- se hacen más claras, como digo, en el momento crítico del desmantelamiento de la República de Weimar y el ascenso de la dictadura Nazi. En una situación políticamente crucial para Europa, ambos se entregan a dos de sus composiciones más ambiciosas. $Y$ los dos lo hacen regresando sus miradas hacia las leyendas bíblicas, es más, hacia los libros del Pentateuco (o la Torá), ya con la liberalidad de un ironista consumado, en el caso de Mann, ya con el pathos de una conciencia religiosa a punto de reganar su identidad abandonada, en el caso del luterano Schönberg (lo era desde 1898), nuevamente el judío Schoenberg a partir de 1932. Trabajan en paralelo: desde 1923, el músico vienés venía dando vueltas a la idea de una ópera en tres actos sobre el episodio de Moisés ante la zarza ardiente, y a partir de 1928 su dedicación fue lo suficientemente intensa como para completar en 1932 el libreto y la partitura de los dos primeros actos. Posteriormente, habría de redactar todavía el texto del tercero. Que quedaría sin embargo exento de música. Moses und Aron (la triscaidecafobia de Schönberg le escatimó una 'a' al nombre del hermano locuaz -lo cual no impidió, quizá al contrario, que el escatimador muriera un día 13-), su obra más monumental del dodecafonismo, habria de quedar incompleta. Aunque nunca una obra incompleta tuvo un final tan perfecto, como veremos. 
Desde 1925, al bajarse de su Montaña mágica, Thomas Mann empezó a esbozar por su parte una tetralogía que ampliaría de un modo inusitado el relato de José, hijo de Jacob, sumarizado en el Génesis. Las cuatro entregas de "José y sus hermanos" se fueron sucediendo entre 1930 y $1943^{1}$. Pero antes de perder el aliento del viejo mito testamentario, quiso en cierto modo darle prolongación a su obra, avanzando unas generaciones en la escaleta del judaísmo: y dedicó a Moisés un potente relato titulado Das Gesetz (Mann, 1990), originalmente concebido para un frustrado filme propagandístico, que acabó formando parte muy destacada de un irregular volumen colectivo editado por Armin L. Robinson, en inglés, publicado en EEUU en 1943 bajo el expresivo rótulo de The Ten Commandments. Ten Short Novels of Hitler's War Againts the Moral Code.

En Schönberg el trabajo sobre el mito mosaico surgió en los prolegómenos de la dictadura nazi para quedar suspendido en el filo mismo de la fecha de exilio (1933); mientras que, en Mann, Moisés fue la figura que le permitió hacer, en medio del peligro $y$, todavía, de la incertidumbre de la guerra (éste es el texto que Mann tenía entre manos mientras los alemanes caían en Stalingrado), la transición entre dos leyendas centrales en la lógica espiritual de 0ccidente, y de su propia aventura novelística: José y Fausto². En cualquiera de los dos casos, el instaurador religioso, el inexorable legislador y tartamudo patriarca de Israel, de nombre egipcio $y$, además, extrañamente truncado (lo de "el salvado de las aguas" es una cándida, popular y falsa etimología seudohebraica, pues mose es al parecer un término egipcio: habitualmente funciona como la raíz de un nombre complejo, tal cual Amen-mose, es decir, hijo o nacido o niño de Amen, e igual Ptah-mose, o Ra-mose, que significa hijo de cada uno de estos dioses; con lo que Moisés es una forma nominal extrañamente rudimentaria e inacabada, o tirando del hilo de su historia personal se podría decir: una forma nominal a secas, huérfana de padre y de dios), este libertador del pueblo judio no fue empleado sin más en las ficciones de Schönberg y Mann como un Icono de la Ley al que ir a protegerse durante tiempos políticamente peligrosos.

Un análisis de las dos obras, el relato La ley y la ópera Moses und Aron, nos permitirá percatarnos de que lejos de utilizar a Moisés como fetiche con el que poder pasaportar la devoción de los exilados centroeuropeos por una Autoridad y un Ethos purificadores, o como grandilocuente alegoría de la Liberación frente al Terror (jugando la infalible baza de asimilar a Egipto con Alemania, y al Faraón con el Führer) ambos artistas transformaron críticamente a Moisés en la leyenda de un tiempo original que, separado por alrededor de 2.300 años del tiempo tardío de Adolf Hitler, quedó ya sembrado por dudas acuciantes que merecía la pena volver a actualizar: ¿cuál es el riesgo de pretender sojuzgar los órdenes profanos de la vida bajo el imperio de la religación sobrenatural de la ética? ¿Hasta qué grado queda debilitado el fundamento de la Autoridad y la fuerza de la Ley bajo la inclinación politeísta de nuestras devociones y el pluralismo mundano de nuestros temores? ¿Cuál es el estilo del mundo de aquel que sueña con un asiento unitario para el Pueblo como comunidad en la Fe a partir de una erradicación violenta de toda contingencia moral?

\section{Thomas Mann: contra Hitler, otra fuerza DE LEY}

Todo comienza en Mann con el nacimiento irregular del protagonista, pues "su padre no fue su padre y su madre no fue su madre" (Mann, 1973, 4). Lector de los artículos que Sigmund Freud habia venido publicando en la revista Imago bajo el título de Moisés y la religión monoteísta (Der Mann Moses und die monotheistische Religion), y en los cuales se había intentado probar la fantasiosa y atractiva hipótesis de la nacionalidad egipcia de Moisés -y aun de un doble Moisés refundido en uno solo por la tradición, tan aplicada en solapamientos de la identidad: el irascible Madianita, que condujo al pueblo judio hasta el oasis de Qadesh a los pies del Sinaí, y cuyo tipo lo había acuñado Jethro, su suegro bíblico, y el templado Moisés egipcio, experto en Aton y líder de faraónicas empresas, devinieron en uno, dice Freud- (Freud, 1981, 54-55), Thomas Mann no perdió la oportunidad de secundar en La ley, precisamente en La ley, esa política tan suya de "Mythos durch Ironie", hasta convertirlo en su relato más lleno de chispa volteriana y más fiel al antidogmatismo lessingiano.

Plegó para ello su serio humor al canon de leyendas que tratan de algún expósito, según el cual un niño nace en una primera familia noble y casi siempre Real para acabar a la puerta de una segunda humilde o degradada, donde crece. En el relato manniano, Moisés, que según el capítulo 2 del Éxodo fue progenie de la tribú de Leví, es fruto ilegí- 
timo de los amores puntuales de un joven aguador hebreo ¡con la misma hija del Faraón! -quien de descubridora en pleno baño de la canastilla del bebé hebreo pasa a joven paridora de un Moisés del más alto linaje egipcio-. Sabedor de su origen, la casa del Faraón dio a este nieto de reyes a una mujer hebrea que lo condujo a Gesén, donde lo adoptó Jochebed, mujer de Amram, que en esas fechas estaba amamantando a su propio hijo Aarón y tenía leche de sobra.

Irregulares orígenes, irregular la crianza de este falso hijo de Amram, por cuya educación superior veló la providencia de su madre biológica, sacándolo de entre las gentes del desierto y dándole, en una refinada escuela tebana, la formación propia de un egipcio en vías de obtener colocación en la corte de Ramsés, su abuelo de concupiscencia... pero la mitad hebrea de su sangre tiraba de él hacia Gesén. Y en su huida habría de asumir en primera persona un acto total de violencia y una muestra de esa iracundia precristiana que tanto cuadra con el arquetipo mosaico: asesinó brutalmente a un egipcio al salir en defensa de un obrero esclavo. El relato de Mann, no obstante, se centra muy pronto, siguiendo el Éxodo a la distancia, en el regreso a Egipto de este madianita de adopción y pone un énfasis especial en la formación de una suerte de guardia de corps capitaneada por un efraimita, Hosea, o Josué, para quien el Invisible de Moisés era antes que nada el Dios de las batallas, y en cuya imaginación guerrera el complejo proyecto judio de la liberación del yugo faraónico se traducía, de forma más realista, por la necesidad de conquista de otra tierra alternativa que ocupar las tribus hebreas. Thomas Mann, siguiendo la pauta del Goethe del West-östlicher Divan (Machoschey, 1998, 89-99), da una relevancia Ilamativa a la figura de Josué, el geógrafo, el estratega, el brazo militar del artista, el ángel exterminador.

Jehová significaba el éxodo. Y éxodo es tanto un viaje a la libertad religiosa cuanto una campaña de conquista, como habrá de verse en el episodio de la toma de Oadesh, la posición paradisíaca vecina al lugar de la revelación de la Ley. El relato de Mann, esto es importante hacerlo notar, no asume como propia la solemne tarea de narrar la revelación de la ética. Más bien emprende la muy ética tarea de ironizar sobre la revelación (con lo cual prosigue la estela de la mejor Ilustración alemana, la de su admirado Lessing). La ley es aquí no la lengua de la Providencia y la santa trinidad del ethnos/demos/fides, sino peleón lenguaje moral, agóni- ca obra de autoridad, violencia como orden de poder: pura forja política. $Y$ ese doble fondo, peligroso por lo reflexivo, sangriento por lo impositivo, del proyecto monoteísta de reunificación de las tribus hebreas, consistente en hacer de esa multitud indecisa de esclavos idólatras un pueblo arracimado en torno a la recuperación de un viejo Dios ancestral cultivado ahora en perspectiva exclusivista bajo el impopular marketing del Yo soy el que soy, ese doble fondo no puede ocultarse, por más que incomode a comentaristas religiosos que, como Karl-Josef Kuschel, se resisten a creer que la lucha manniana en favor de la decencia moral pueda tener éxito si no es a través de la Ley en tanto garantía de un vínculo universal con lo Absoluto e Incondicionado (Küng; Kuschel, 2006, 416-431).

La ocasión recurrentemente propicia para la irascibilidad de Moisés es la resistencia de las tribus a conceder que la Alianza con el Dios Invisible no es contraproducente para su condición de víctimas de la opresión. En la lógica de los ancestros, Yahveh, el Dios de Abraham, Issac y Jacob, se había disuelto en una deidad del mero por si acaso, un dios garantista, el dios del horror vacui sentido genialmente por el politeísmo de los primeros judíos desperdigados: hay que agotar las posibilidades de encontrar lo divino, consagremos entonces, para cubrirnos las espaldas, un dios a esa mera posibilidad de encontrar divinidad en el vacio, por si acaso hay dioses cuyo régimen de existencia y poder se coloca más allá de los ojos, los cuerpos y la presencia. Yahveh fue durante mucho tiempo el lugar reservado en el panteón judío a la mera probabilidad. Y ahora Moisés escogia a ese Yahveh, al dios difícil, axiomático, potencia del por si acaso y de la no presencia (o de la esencia sin presencia), y le decía el Salvador, y el Único.

Mann toma nota además de la dificultad personal del legislador, Moisés, que a solas se entiende tan bien con el Dios de la zarza, para transformarse ante las tribus en un Icono de la Ley eficazmente comunicativo: la Alianza de Dios con Israel pasaba por una alianza entre los hermanos políticos, es decir, el colérico y tartamudo profeta del Invisible habría de servirse del carnal y locuaz Aarón, con lo que la misión mosaica, que Thomas Mann describe en términos escultóricos (abundando en referencias a Miguel Ángel, aprendidas de Heinrich Heine, quien en sus Confesiones de 1854 ya vistió a Moisés con las galas del artista, cuyas obras de arte no estaban hechas de ladrillo como las de los egipcios, pues él era constructor de pirámides 
humanas, escultor de humanos obeliscos) es vista como un "modelar al pueblo de Israel a imagen del Dios Invisible" que necesita la subvención hermenéutica de Aarón, la boca de Moisés, en quien late de manera más desembozada el pulso y las querencias naturales del pueblo, hasta participar de ellas como sacerdote eminente de sus tentaciones. Pero de manera mucho más aguda que en la versión manniana, las dificultades de imponer el monoteísmo a través del pluralismo, y la querella entre las facultades fraternas, será, como veremos, el núcleo del Moisés según Arnold Schönberg. En todo caso, tanto Schönberg como Mann ponen en claro una perspectiva: lo artístico del caso no es la "invención" del monoteísmo, sino las penosas dificultades de activarlo en la historia. Cuando el decálogo mosaico reza en primer lugar "No habrá para ti otros dioses delante de mi" (Éx. 20,3) es la misma palabra de Yahveh la que constata la existencia de múltiples dioses. Eso ni Dios lo discute. Por ello, dice Gerhard Kaiser, "no se trata de la promulgación del monoteísmo, sino de su puesta en práctica" (Assmann, 2006, 196).

Que no hay fe popular sin una buena corte de Milagros eso es algo que sabe Aarón, y también su hermana, la profetisa María, la dionisiaca bailarina; pero que se resiste a conceder el purista Moisés ( $y$, especialidad en Mann, todo purista esconde a un sensualista: el relato resalta la importancia de cierto capricho etíope de piel oscura), que quiere innovar yendo hacia atrás. Aarón entiende la lógica espiritual del pueblo, que es una lógica de la visibilidad: si se nos escatima la eficacia visionaria del milagro, la alternativa es un acto de violencia persuasiva, un dios que nos haga afortunados en la guerra, un dios incontrovertiblemente demoledor del contendiente, pues si este Dios siente vergüenza de las exhibiciones sobrenaturales, al menos habrá de convencer de la realidad de su poder por la vía secular de su potencia militar (y que el enemigo muera con un iTodo está perdido! ¡Yahveh está sobre nosotros! en los labios), máxime cuando exige que se le reconozca como el Único.

Por eso el relato de Mann es exquisito en el retrato de la labor moralizadora sin la cual es imposible imponer eficazmente a un Dios así. Cuando las masas se aprestan a celebrar jubilosas la devastación de las tropas del Faraón en el episodio del Mar Rojo, a Mann, ciertamente incapaz de competir con Cecil B. DeMille, le interesa la aventura moral que emprende en esa ocasión Moisés:
No bien dio María término a su danza, Moisés prohibió toda otra manifestación de júbilo por la destrucción de las fuerzas egipcias. Anunció para ello que las huestes angelicales de Jehová habian estado a punto de unirse al cántico triunfal, cuando Dios les había indicado: "¡Cómo!, ¿mis criaturas perecen en el mar y vosotros os regocijáis?" Moisés hizo circular esta historia breve y sorprendente que llevaba el siguiente corolario: "No celebrarás la caída de tu enemigo; el corazón no se alegrará por su desventura".

Era la primera vez que aquella masa de gente [...] oía que se dirigían a ella en forma de "tú", una forma que al par que los agrupaba a todos en uno, se dirigía a cada uno particularmente: marido y mujer, anciano e infante. Conmovió inmensamente a todos sin distinción, como si un dedo divino los hubiera tocado en el pecho. "No te regocijarás por la desventura de tu enemigo..." se les antojaba totalmente ajeno a lo lógico y natural. Pero seguramente esa falta de naturalidad debía atribuirse a la invisibilidad del Dios de Moisés, que deseaba convertirse en su único Dios. Y entonces, los más inteligentes de entre tantos, comenzaron a intuir el significado de aquello y cuán difícil e irreparable resultaria el haber jurado obediencia a un Dios invisible (Mann, 1973, 123-124).

En primer lugar, es deliciosa la ironía del escritor al pintar un tiempo tan "original" en que hasta los ángeles están indecisos y no saben cuáles son los modales que han de observar en las victorias. Luego se recoge muy bien, además, esta ambigüedad de la labor de reagrupamiento espiritual de la masa a cargo de Moisés: que dedica ese "tú" que al tiempo une y distingue, un tú que a la vez factura comunidad e individualidad. Como un adviento de la Ley, la moral mosaica echa de ver antes que nada su extrañeza: ése es su dato radical, el sacrificio que exige lo desacostumbrado. Se trata de algo a lo que, por distintas razones, entre las que podemos contar sus intensas lecturas de Nietzsche, Thomas Mann era particularmente sensible: la moral no es el espejo de la naturaleza, menos aún cuando aquello a lo que apunta es a validar lo sagrado. Moisés, moralizador antes que legislador (o que estima al menos que la moral es la propedéutica de la eficacia de la ley), intenta denodadamente mostrar que la existencia social de Israel como comunidad en la Fe sólo es posible a través de procesos de relegación que conciernen, básicamente, a la corporalidad y su represión, y al poder y sus exclusiones. Sólo así la moral es una fuente de existencia social: a través de la justificación de las restricciones en el sexo indiscriminado 
y el poder irracional. Leyendo a Mann, leyendo al Moisés de Mann, podríamos acordarnos, ciertamente, de la definición de lo sagrado por la que opta por ejemplo Maurice Godelier en El enigma del don:

Lo sagrado es un cierto tipo de relación con los orígenes en la que, en lugar de hombres reales, se instalan dobles imaginarios de éstos. En otras palabras, lo sagrado es un cierto tipo de relación de los hombres con el origen de las cosas de una índole tal que, en ella, desaparecen los hombres reales y aparecen en su lugar dobles de sí mismos, hombres imaginarios. Lo sagrado sólo puede surgir si desaparece alguna cosa del hombre. Y el hombre que desaparece es el hombre coautor, junto con la naturaleza, de sí mismo, el hombre autor de su modo de existencia social, de su ser social (Godelier, 1998, 245).

El ethos de este héroe fundador que es Moisés, pasa por intentar convencer a las tribus de que no tienen realidad propia, que todos ellos son seres obrados, cuya vocación ha de ser la de alcanzar a convertirse en imagen de lo Invisible, puesto que el orden de su universo es el favor de un único dios ("su pensamiento se concentraba en torno a una sola idea: la de agrupar al pueblo de su padre en torno a sí, de forma que pudiera moldearlo a su deseo y hacer a esa masa informe que tanto amaba a imagen del Dios Único e invisible", escribe Mann).

Das Gesetz recoge, por otra parte, cómo un proyecto tan exigente como el de la iconoclasia mosaica exige la compensación de una cierta parafernalia sacerdotal: y así, como otro adviento de la Ley, la institución del tabernáculo erige al pueblo pusilánime un altar en el oasis de Qadesh en que guardar esos objetos pregnantes, el arca, el báculo de bronce y cabeza de serpiente, el efod o bolsa para echar las suertes, el urim/tummin, el sí y el no que deciden en caso de agravios sobre lo justo o lo injusto, objetos que le curan a las tribus de sus desconsuelos por la ubicuidad e invisibilidad del Dios de aquel "que les sacó de Egipto".

Quiero traer aquí, al amor de la iconoclasia, una referencia que va a ser en adelante oportuna: Walter Benjamin escribió en 1921 uno de sus textos más decisivos, Zur Kritik der Gewalt (Benjamin, 1977, 179-203), y Jacques Derrida incluyó como segunda parte de su excelente texto Fuerza de ley, una lectura del mismo de la que extraigo una nota que quizás permita enlazar la iconoclasia del Moisés manniano con la crítica de Benjamin a la representación no sólo como perversión y caída del lenguaje sino como sistema político de la democracia formal:

La lógica profunda de este ensayo lleva a cabo una interpretación del lenguaje - del origen y de la experiencia del lenguaje- según la cual el mal, es decir, la potencia letal, le viene al lenguaje por la vía, precisamente, de la representación, es decir, por medio de la dimensión re-presentativa, mediadora, y en consecuencia, técnica, utilitaria, semiótica, informativa, otras tantas potencias que arrastran al lenguaje y lo hacen caer e ir a parar lejos o fuera de su destino original que fue la apelación, la nominación, la donación o la llamada de la presencia en el nombre (Derrida, 2008, 71).

Thomas Mann, ironista, sabía que su tiempo era el tiempo de la lengua posadámica, y que las nostalgias del Ursprung nominativo podrian dar en verdaderas atrocidades ${ }^{3} ; \sin$ embargo, en un pensador de tanto ascendiente mesiánico como Benjamin, la denuncia de una violencia que llega a y en la representación no deja acaso de ofrecernos una pista crítica de cuál era el horizonte que hizo posible que la iconoclasia antiidolátrica del viejo Moisés resucitara temáticamente, y por doquier, en múltiples figuras del arte y la ficción, en aquella centroeuropa en los aledaños del nazismo.

Pues la pregunta que se hacian los hebreos era ¿cómo coordinar el derecho con este Dios único de la no presencia y la invisibilidad? La primera de las ocupaciones de Moisés una vez establecido su pueblo en las mismas faldas del Sinaí fue administrar justicia. Y dice Mann, con toda la intencionalidad que era posible conferir a este pasaje el año 1943, que la idea misma de "derecho" le era incomprensible a aquella secta perdida...

A decir verdad, no puede decirse que supieran lo que esa palabra significaba... agravada la ignorancia por el hecho de tener que asociar el "derecho" con la invisibilidad del Dios y su santidad, y considerarlo como emanación directa del mismo Dios. Y lo que es más, oían que en esta nueva idea del derecho iba incluida la idea de culpa, conclusión que la mayor parte del pueblo tardó mucho en captar. Pensaban ellos al principio que debia hacerse justicia a cuantos alli acudian, es decir, darles la razón. Se resistían a creer que también se administraba justicia a un individuo, aun cuando se lo considerara culpable y debiera retirarse del lugar con la cabeza 
gacha. Este individuo, por supuesto, echaría una maldición y se lamentaría de no haber solucionado la disputa con su contrincante en la forma natural y acostumbrada, es decir, piedra en mano, con lo que los resultados pudieron haber sido bien diferentes. Muy lentamente fue penetrando en sus espíritus el principio de que semejantes ideas no guardaban armonía con la invisibilidad de Dios, y que quien era juzgado culpable por la ley no debía por eso considerarse vilipendiado, pues la ley es siempre austera y digna en su pureza invisible, otorgue o no la razón (Mann, 1973, 136-137).

El tropel de gentes que acudian a Moisés a dirimir sus disputas era tan ingente que la administración de justicia se convirtió pronto en la esfera de mayor ocupación y relevancia en la vida social judía. Se precisaba una racionalización de su funcionamiento para que Moisés no quedara desbordado y exhausto. Por inspiración de Jetro, aquí hermano de Séfora, su esposa, y tal como si el Moisés manniano hubiera leído a Weber, establece una suerte de corte de justicia en que por obra de la delegación de poderes funcionariales y del establecimiento de instancias de apelación, y a cambio de asumir como mal necesario una cierta cuota diabólica de corrupción en alguna de las partes cuyos efectos se encargaría de corregir el sistema, Moisés se hace con un cuerpo burocrático que produce en el cuerpo de su sociedad un deslinde estratégico, sólo cuando Moisés satisface las demandas de justicia civil queda él liberado para emplearse a fondo en la pedagogía de la Ley divina: Eso sería -dice Mann- una parte de la tarea, y la más fácil, porque muy otra cosa sería hacer algo extraordinario del pueblo, convertirlo en una comunidad aparte y santificada, purificada, con sus ojos fijos en el Invisible y a Él sólo dirigidos.

\section{* * *}

Hasta aquí un itinerario por esos advientos de la Ley, por su propedéutica, por los poderes y límites que la preceden: la liberación que es conquista de tierra (la toma de Qadesh); la moralización que es relegación de los poderes del cuerpo (hay una cuidadosa anotación en el relato de las restricciones que afectan tanto a la higiene y la dieta como a la lujuria, ámbitos de disciplinamiento básico); la existencia social que le produce al hombre natural un Doppelgänger en su imaginación (os he separado para que fuerais míos, dice Moisés que dice Yahveh); la racionalización en la administración de justicia que por una parte enseña a distinguir entre derecho y subjetividad (algo así como un memento de la época en que el hitlerianismo más incidía en la cesura entre ley y justicia), y por otra habilita funcionalmente al héroe fundador en su empeño de pedagogo de las cosas últimas; y, finalmente, como hemos visto, la iconoclasia, tic de un dios celoso: "La más grande impureza de todas es la de que os preocupéis de otros dioses fuera de Mí, porque yo soy un Dios celoso. Y lo peor de todo es hacer una imagen, sea de hombre o mujer, buey o gavilán, pez o gusano, porque con ello os habréis apartado de Mí, aun cuando esa imagen quisiera representarme a Mí" (Mann, 1973, 145).

La consternación popular iba en aumento conforme se les hacía cada vez más claro lo que suponía haber caído en las manos de un hombre como Moisés, cuyo Yahvéh (al que a veces, en una sinécdoque espiritual, confundian con él) les pedía que interpretaran preceptos como los de no matar u honrar a los progenitores de una manera en exceso amplia, escrupulosa y exigente. Moisés se sentía rodeado, de un lado, por la actitud odiosa de Aarón que le envidiaba su condición de elegido, de otro, por la actitud de un pueblo que sólo con la sonada convocatoria de Moisés al Sinaí, epifanía volcánica mediante, pareció convencerse de las ventajas de la Alianza y de la salida de Egipto.

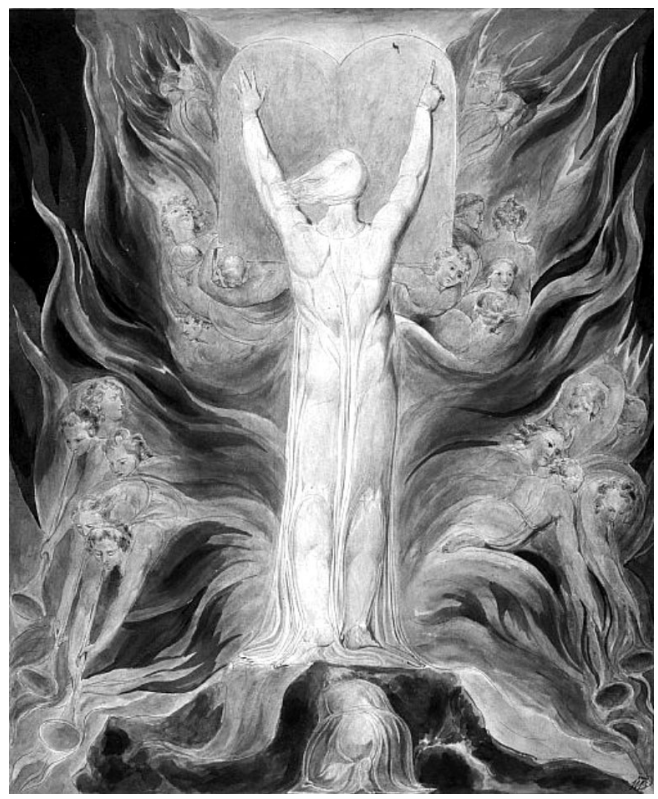

Ilustración 2. William Blake: "God writing upon the Tables of the Covenant". 
Lo que interesa a Mann de esta conocidísima escena de los 40 días y sus 40 noches de Moisés en lo alto de un sulfúrico Sinaí (ahora sí que como un Miguel Ángel devenido en un Benveniste, pues aplicándose sobre la roca para grabar la Ley, le surge la duda de en qué lengua tallar las leyes en las piedras, por lo que ha de aplicarse también en la invención de un alfabeto universalmente combinable), es su no menos célebre corolario: lo primero que hace la Ley (No matarás, No cometerás adulterio, No robarás, No perjudicarás al prójimo con falso testimonio, No codiciarás los bienes ajenos, por recitar los mandamientos que le cupieron en la mano izquierda) es hacerse trizas. Ésa es la primera función de la Ley divina al contacto con su horizonte de recepción: romperse.

La espera de la Ley (y deberíamos recordar a este respecto el siempre asombroso relato de Kafka) ha producido profundos cambios en ese horizonte de recepción: formado ahora por una comunidad rota que ha distraído con la bacanal del becerro de oro su impaciencia por la ausencia tan dilatada de aquel que los sacó de Egipto (¿y si había muerto allá arriba?).

La reescritura de la Ley (y el esfuerzo de un señor mayor de volver a escalar el Sinaí una vez aplacados los éxtasis de la danza y los idola) no es un acto clónico del primero. Es una actividad igual que persigue en cambio un fin contrario: Moisés, tras esa explosión de violencia contra su pueblo cuyo hito fue estampar la Ley contra el ídolo, ha aprendido definitivamente la diferencia que Walter Benjamin pusiera nuevamente de relieve en pleno siglo XX y que Derrida resume como distinción entre dos violencias del derecho: la violencia fundadora, la que instituye y establece el derecho (die rechtsetzende Gewalt) y la violencia conservadora, la que mantiene, confirma, asegura la permanencia y la aplicabilidad del derecho (die rechtserhaltende Gewalt) (Derrida, 2008, 82). La primera vez que bajó del Sinaí, Moisés era un confiado padre fundador del derecho de Israel a su existencia. La segunda se había convertido ya en un padre necesariamente conservador de unos mandamientos tan cuidadosamente tallados por dos veces. Derrida introduce de la mano de Benjamin dos distinciones ulteriores en que no podemos detenernos; pero que no podemos tampoco olvidar al leer Das Gesetz:

Hay a continuación la distinción entre la violencia fundadora del derecho, a la que se Ilama "mítica" (hay que sobreen- tender "griega", me parece), y la violencia destructiva del derecho (Rechtsvernichtend), a la que se le Ilama divina (hay que sobreentender "judia", me parece). Hay en fin la distinción entre la justicia (Gerechtigkeit) como principio de toda fundación divina de fines (das Prinzip aller göttlichen Zwecksetzung), y el poder (Macht) como principio de toda posición mítica de derecho (aller mytischen Rechtsetzung) (Derrida, 2008, 82).

Quizás las tribus hebreas presintieron que lo que se cocía en el Sinaí era la amenaza de la Ley, o la Ley como amenaza: $y$, como dice Derrida, la ley se muestra amenazante a la manera del destino. Israel teme aquello en que se escribe su condición de pueblo elegido: el destino. El episodio de la destrucción del becerro de oro es la explosión de una violencia, la de Moisés, destructora del derecho que Aarón había conferido a las masas en su ausencia, derecho a fundarse el mito de un dios visible (que pedía también sus entretenidas violencias, en forma de bailes, sacrificios y holocaustos). Aarón es el organizador de esa violencia fundadora de mentiras y donadora de poder que es repelida por la fuerza destructora de Moisés, cuyo fin divino consiste en hacer del pueblo Uno... por lo que el innovador Moisés habrá de reutilizar en el futuro todas sus violencias con el objetivo de conservar sus divinas leyes, algo que se transparenta en la invocación que cierra el relato.

Pero prefiero no citar directamente del relato estas entonadas palabras, prefiero hacerlo a partir de una alocución radiofónica de Thomas Mann al pueblo alemán a través de la British Broadcoasting Corp., con fecha de 25 de abril de 1943, en que presenta el nuevo libro sobre los Diez Mandamientos a los radioyentes de la Alemania de Hitler, y ofrece un encaje político a su Das Gesetz como argumento libre contra "la blasfema profanación que de esa ley fundamental de la moral humana realizan las fuerzas maléficas contra las que ha tomado por fin las armas, tras larga demora, un mundo que sigue creyendo en la religión y en la humanidad", atreviéndose, en uno de sus habituales ejemplos de alta autoconciencia y de excelente propaganda moral, a establecer un parangón entre sus emisiones para la BBC y las "emisiones" del Moisés del cuento ante su pueblo...

Y como las palabras con que hizo entrega de las tablas de la Ley a su pueblo entonan perfectamente con el carácter de estas emisiones mías, radioyentes alemanes, vais a oírlas 
ahora, como primicia [...] "Correrá la sangre a torrentes por causa de su negra estupidez, correrá la sangre hasta quedarse lívido el rostro de la humanidad; pero no hay más remedio: es preciso abatir al infame. $Y$ alzaré mi pie, dice el señor, y le hundiré en el fango; hundiré al blasfemo limo, ciento doce estados bajo tierra, y hombres y animales harán un cerco en torno al lugar donde yo le hundi, y los pájaros del cielo que se ciernen en lo alto evitarán volar sobre aquel paraje. $Y$ el que pronuncie su nombre escupirá a los cuatro puntos cardinales y se limpiará la boca y dirá: '¡Guarda!'. Que la tierra vuelva a ser la tierra, un valle de lágrimas, ciertamente, pero no un campo cubierto de carroña. Decid todos: Amén" Y todo el pueblo dijo: Amén (Mann, 2004, 156-157).

\section{Schönberg el inconcluso, Schoenberg EL INCONCUSO. UN FIN, MoISÉS, DERROTAdo. UN SINFín, MoISÉS, VICTORIOSO}

Si hay una obra que pone en escena, con una seriedad casi imposible de ridiculizar, los modelos de conciencia de la modernidad alemana durante la fechas criticas de la República de Weimar, si hay una obra que retrata algo así como el sintoma de Weimar, esa obra es "Moses und Aron", de Arnold Schönberg.

En el trascurso de la historia aparecen épocas especialmente dispuestas para el cinismo -dice Peter Sloterdijk-, épocas que en una terminología marxista serían las del decadente dominio de clases; épocas de una ideología reflexivamente construida, en las que las normas y los dogmas de la cultura, amortiguados autoirónicamente, empiezan a jugar con sus contradicciones internas. En la historia de la humanidad hasta ahora acaecida, el hecho de que se hicieran reflexivas situaciones de conciencia falsas y perversas era siempre síntoma patológico de cultura, expresión de que los estratos dominantes habían iniciado un estadio mórbido que se inclinaba al asilvestramiento y la desinhibición. [...] Se trata de épocas tardías en las que las fuerzas originarias, las ingenuidades de valor estable y las tensiones volitivas primigenias se han consumido en los niveles de dominación cultural a través de procesos de aprendizaje estratégicos. Por consiguiente, cínicamente dispuestas están esas épocas de hueco gesto y de fraseología refinadamente tramada, en la que bajo cada palabra oficial se ocultan reservas privadas, mundos contrarios e ironias y cuando bajo las manifestaciones oficiales fluyen mudos submonólogos de los que sólo el introducido, el corrupto, el decadente, el irónico comprende algo. La sonrisa de los augures es también la sonrisa de las clases dominantes que perecen (Sloterdijk, 1989, 209-10).

Valgan estas palabras, brillantes y quizás ciertas, de Sloterdijk para ambientar la resurrección de Moisés en el dodecafonismo $0^{4}$. Pues en ocasiones se ha querido hacer pasar a Schönberg por uno de esos que practicaron la altanería del iniciado para sobreponerse al cansancio o el absurdo, y a la escritura dodecafónica por un ejemplo de ese vocabulario patográfico de la crítica cultural weimariana que en realidad no era sino una salud fingida en exceso segura de sí misma. Creo que Moses und Aron demuestra que había otras disciplinas además de la del cinismo con que auscultar la bancarrota que precede a la dictadura.

De hecho, Moses und Aron es una obra del exilio que precedió al exilio: en 1924 Schönberg había abandonado definitivamente la República austríaca, asqueado por la ola antisemita de la que había dado buena prueba por ejemplo el ayuntamiento de la localidad del Salzkammergut en que pasaba sus veranos, al expulsar a los judios practicantes y exigir a los otros que acreditaran una partida de bautismo. Por tercera vez en su vida se instala en Berlín, tras aceptar el ofrecimiento del ministerio prusiano de Cultura para que ocupe la vacante que había dejado Busoni al frente de la cátedra de composición en la Akademie der Kunst. Serán siete años de tregua relativa, de exilio antiaustriaco que antecedió al exilio antihitleriano, antes de proseguir su viaje sin retorno a California, vía París. Moisés y Aarón (1932) es la obra-límite desde la que auscultar la crisis de Weimar desde la conciencia de una suerte de exiliado interior como era aún Schönberg en esos años, uno de los primeros músicos en captar la gravedad y la extensión del mal al abandonar Berlín y Europa en 1933, para no volver jamás -al poco, otros como Schreker, Berg y Webern moririan en muy diversas circunstancias, y otros más como Egon Wellesz, Ernst Krenek o Hanns Eisler habrian igualmente de exiliarse- (De La Grange, 2002).

De forma complementaria al Moisés de Mann, cuya sombra goethiana era el militar Josué, en la ópera de Schönberg la sombra del protagonista -y una sombra protagonista, por cierto- es Aarón. ¿Una ópera-oratorio basada en un personaje, judío para más señas, que tiene atroces dificultades 
para expresarse y necesita una boca? La fuerza expresiva y teatral del Moisés schönberguiano viene dada por la modalidad de escritura que le reserva la partitura: un imponente Sprechgesang (canto hablado, un fraseo dinámico recitado) o Sprechstimme (voz hablada), en cualquier caso obediente a una notación que observa perfectamente las asignaturas rítmicas e interválicas. Sin embargo, la parte de Aarón es la de un cantante. Nos equivocaríamos si pensáramos que con esto el autor ha querido marcar sencillamente una dialéctica entre mudez y locuacidad, entre la parálisis verbal de uno y la comunicatividad expansiva de otro. Veamos qué es lo que aquí se esconde.

En el Acto I, Moisés se confronta a Dios (cuya voz politextural es irreductible a un solo timbre), al que incansablemente asocia los abultados atributos de Único, Eterno, Omnipresente, Invisible e inimaginable. El primer trastorno para una caracterización semejante lo padece Moisés cuando escucha al propio Dios el encargo: "¡Ahora, anúnciame!". "Tú has despertado en mí la Idea, no me obligues a anunciarla", le responde Moisés. "Has visto los horrores, has conocido la Verdad... no puedes hacer otra cosa: debes liberar a tu pueblo", le insiste. "Mi lengua no articula, puedo pensar pero no hablar...", se excusa el hombre de la Idea. Yahveh provee una solución que a la postre se convierte en el corazón de la ópera: iluminará a Aron, "él debe ser tu boca, tu voz ha de salir de Aron igual que la mía sale de ti". Pero el encuentro de los hermanos en el desierto no hace sino poner en claro el conflicto fundamental entre ambos: Moisés piensa la Gracia como conocimiento puro y Aarón la traduce más fácilmente por amor y sangría popular. Invisible, Irrepresentable, Infinito, Todopoderoso... ¿cómo hacer una hermenéutica de un dios así?, se pregunta Aarón, quien tiene una vena que lo comunica con la horda, con la tribu, y sabe que la adoración no sólo admite sino que exige un régimen de lo sensible que aclare de qué especie han de ser las relaciones con lo adorado ("Adorarle, ¿a quién? No lo veo. ¿Debemos amarle o temerle? ¿Dónde está? ¡Muéstranoslo! Queremos llevarle ofrendas ¿Tu dios todopoderoso no tiene el poder de mostrarse?", dice el coro-pueblo).

El Moisés de Schönberg es un héroe de la impotencia: y su primera impotencia, así lo cree él, consiste en contemplar su Idea encarnada en la boca de Aarón. Esta deflación del pensamiento de la divinidad en la boca mundana de Aarón es algo que desespera a Moisés, cuando en realidad dicha deflación forma parte del programa diseñado por Yahveh para anunciarse y unir a Israel. Por una vez, el oyente debe atender más a este plan dialógico de Yahveh que a las desesperaciones de una de las partes, Moisés (que de buena gana hubiera aniquilado la increíble burocracia del diálogo a través de su hermano).

De otro signo es la compleja relación que se establece entre Moisés y Aarón en la obra schönberguiana, cuyo tema no se reduce al enfrentamiento de la iconoclasia mosaica con la idolatría. En Moisés y Aarón hay que ver más bien una lectura trágica de lo que, para decirlo con palabras del propio Schönberg, constituye en la diáspora el fundamento de la conciencia colectiva del judaísmo: el "constante ocuparse de la Palabra de Dios". Lectura en la que comparecen, aunque desde la clave que aporta la tradición judaica, las instancias en que Schönberg había centrado su reflexión estética desde años atrás: el pensamiento, la palabra, y su pertenencia mutua (Pons, 2006, 186).

Massimo Cacciari, en el capítulo titulado "La boca di Mosè" de su libro Icone della legge, ha observado con especial delicadeza lo más difícil, lo evidente: cómo el nudo de "Mose und Aaron" estaba en el "und", en aquel "y" que nunca como en Schönberg ha sido escuchado con una conciencia tan intensa del abismo que oculta. Pues Moisés y Aarón forman una polaridad (polarità), una dimensión en la que lo originario es precisamente la rotura de la identidad, es decir, el hecho de que la identidad consiste en este polemos que no conoce paz, que no conoce término, que no puede resolverse ni por la vía de la independencia de sus agónicos términos ni por la de su conciliación (Cacciari, 2002, 159).

También en esta versión Aarón cumple el expediente bíblico y se entrega a regalar a la muchedumbre su retahíla de milagros. Pero nunca como en la caracterización de Schönberg los prodigios de Aarón (el báculo que se relaja como serpiente, la sanación de la mano leprosa, la alegoría del agua tornada en sangre y otra vez clara) fueron tan funcionales (dicen las tribus: "Todo por la libertad, destruid a los sacerdotes, matad a los jefes, destruid sus dioses, ial desierto!"): pues no son la expresión de un pequeño subalterno que busca el poder envidioso en ausencia del hermano sino maravillas que, mal que le pese a Moisés, transforman a la Ley en sabiduría. Aarón es el artista en quien Moisés, el profeta, padece la experiencia de los lími- 


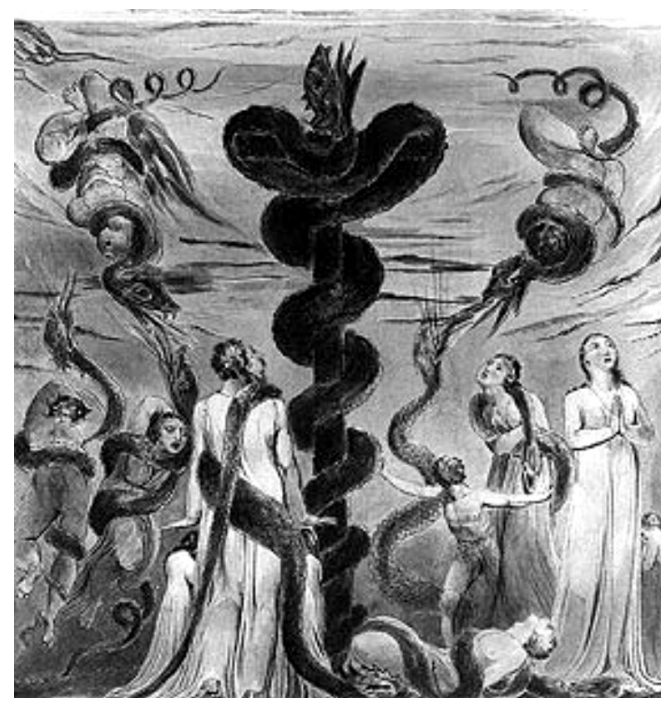

Ilustración 2. William Blake: "God writing upon the Tables of the Covenant".

tes del lenguaje: pues, a diferencia de la versión manniana, que como hemos visto seguía la intuición de Heine, en Schönberg Moisés pierde casi por completo los atributos de un artista, adquiriéndolos a cambio su hermano, elocuente, imaginero, mago. Aarón, en todo caso, expresa bien una de las caras de la propia ambigüedad religiosa del compositor, quien si por una parte estaba interiormente convencido de que lo más importante jamás debía esclerosarse en la palabra, estaba por otra muy alerta del peligro del solipsismo mosaico.

También la escena, musicalmente prodigiosa, del becerro de oro (la tercera del Acto II) cobra aquí tintes insospechados: " $\mathrm{N}$ No esperéis antes la Forma que la Idea! Las dos aparecerán a la vez", dice Aarón a la masa impaciente, volviendo a cumplir aquí también el expediente del hombre que reúne pensamiento y acción. Sólo cuando entre las tribus se extiende el rumor de que Moisés bien pudiera ser que hubiera muerto, sólo entonces condesciende Aarón en un gesto de ministro populista y conocedor de las debilidades: "pueblo de Israel, os devuelvo a vuestros dioses, dejad la lejanía al Eterno. Los dioses que os convienen son de naturaleza concreta y cotidiana". Lo cual celebra el pueblo: "dioses, señores de los sentidos. Vuestra presencia visible garantiza nuestra seguridad. Vuestros límites mensurables no exigen aquello que niega nuestro espíritu". La vuelta de
Moisés con las tablas de los mandamientos, pues la Ley es siempre lo que está de vuelta, con su trágico "iAarón, ¿qué has hecho?! Desaparece, imagen de la incapacidad", es seguida de la apología del mundano:

- Aarón: $\quad$ Cuando te aíslas te creen muerto. El pueblo ha esperado la palabra de tu boca, de donde saldrían los derechos y la ley. Por eso tuve que darles una imagen para que la contemplaran.

- Moisés: Tu imagen desaparece ante mi Palabra.

- A.: En tu palabra se negaban las imágenes y los milagros, por ti desdeñados. Y por lo tanto, al destruir tu Palabra mi imagen, el milagro no fue más que una imagen.

- M.: La eternidad de Dios destruye el presente de los dioses. Esto no es una imagen ni un milagro (Wunder): Ésta es la Ley. Expresa lo inmortal en lo mortal de tu boca. [...]

- A.: Ningún pueblo puede creer si no siente.

- M.: No me convences. ¡Debe aferrarse a la Idea!

- A.: Ningún pueblo toma más que una parte de la imagen (Teil des Bildes) que a su vez expresa parte de la Idea expresable. ¡Hazte inteligible!

- M.: ¿Quieres que falsifique la Idea?

Y así llega el momento crucial, que da fin al segundo acto $y$, puesto que quedó sin musicar el tercero, también a la ópera tal como hoy se escenifica: la derrota de Moisés, que no es tanto una derrota ante Aarón como ante sí mismo: "-Aarón: También las tablas, a las que Moisés está unido, son sólo una imagen, una parte de la Idea. -Moisés: Pues bien, destruiré estas tablas". Aarón sale al paso de esta crisis de la Ley mediante la magia de una columna de fuego que vuelve a insuflar ánimo en el coro acerca de la fortaleza de Yahveh. Igual que Aarón, Moisés está destinado a hacer imágenes del necesario errar (Pons, 2006, 190). Y como dice Marc-Alain Ouaknin en El libro quemado, "Moisés no transmite, en un primer momento, la Ley, sino su fractura; su imposibilidad de ser ídolo, lugar de perfección, libro total" (Ouaknin, 1999).

Schönberg pone por eso en boca de Moisés la derrota que su otra boca, su hermano, no concibe: "iDios inconcebible! ¡Inexpresable, ambivalente idea! ¿Permites esta interpretación? ¿Aarón, mi boca, debe hacer esta imagen? ¿Incluso yo he hecho una imagen, falsa como cualquier imagen? ¡Estoy vencido! ¡Todo lo que había concebido era 
demencia, y no puede ni debe ser dicho! ¡Oh palabra, tú, palabra, que me faltas!"

Es difícil pensar en un final más perfecto para una ópera sin final. Pero la ópera continuaba. $Y$ del inconcluso Schönberg hemos de pasar al inconcuso Schoenberg. Del luterano al judío. En un tercer acto irrepresentable -pero del que llegó a redactar hasta cuatro versiones- le escribió una victoria a Moisés en forma de apología del desierto, es decir, aquella Wunschlosigkeit der Wüste o pérdida de la voluntad que acontece más allá de los impuros límites de la exterioridad de las palabras y las magias en que se petrifican los ideales. Con lo que este icono de la Ley lo es al fin y al cabo del exilio y la ascesis de la errancia sin final, prefigurando el gran sintoma de Weimar.

Aarón, el popular hermeneuta, el artista y mágico prodigioso, aparece encadenado, prisionero, y es arrastrado por los soldados, que lo agarran de los hombros, mientras los 70 ancianos marchan tras él:

MOISÉS: Cada vez que os mezcláis con otros pueblos y utilizáis vuestros dones, vosotros que habéis sido elegidos para poseerlos y para luchar por la Idea de Dios y empleáis vuestros dones para fines falsos y vanos, para competir con pueblos extranjeros y participar asi de sus bajas pasiones, cada vez que abandonáis la renuncia al desierto y que vuestros dones os eleven a supremas alturas, cada una de esas veces caeréis y os precipitaréis nuevamente al desierto, empujados por el éxito de los abusos. [A los soldados] Liberadlo, y si es capaz, que viva. [Aarón, liberado, se pone en pie, y al punto cae muerto].

Pero en el desierto sois invencibles y conseguiréis vuestro objetivo: uniros a Dios.

Como observa Josep Casals, en alguna medida Schönberg compartía desde un punto de vista político la condena de Moisés, el profeta, a Aarón, el artista: si a quien posee la verdad le está vedado el canto, "quien posee la elocuencia, la capacidad de encantamiento, acaba subordinando la verdad a este lazo persuasivo" (Casals, 2003, 392). Sin embargo, la posible identificación de Schönberg con Moisés en la idea, común a ambos, de que hay que resistirse radicalmente a "cristalizar a Dios en la palabra", queda fuera de la representación. Lo cual, al fin y al cabo, no deja de resultar coherente. La victoria de Moisés es precisamente lo inescenificable.
Schönberg se alinea del todo junto a Moisés sólo cuando Aarón cede y renuncia a esa dialéctica entre idea y forma que él mismo ha formulado, cuando sacrifica "lo extraordinario a lo ordinario" y olvida la aspiración de eternidad en beneficio del brillo mundano -esto es, cuando pasa de la estética al esteticismo-. Sin embargo, se separa de Moisés cuando éste, a su vez, olvida que todo en nuestro universo es imagen y símbolo, también su bastón y sus tablas. Y que ese orden simbólico no remite a ninguna ley natural, sino sólo a su propia legalidad y a su interacción con otros órdenes (Casals, 2003, 396-397).

Desunidos, desamparados, muerto cualquiera de ellos, Moisés y Aarón representan por separado dos riesgos políticos, dos formas peligrosas de alentar la comunidad: el fundamentalismo de la Idea y el esteticismo de la Imagen. Moisés, el héroe moral marcado por la experiencia de su impotencia, el tenaz enemigo de la milagrería, el idealista que se lamentaba por la falta de la palabra y al que la cólera le fracturó la Ley convirtiéndola, muy sintomáticamente, en una ausencia, seguida de un remake, ese Moisés "débil" era en Schönberg la figura que más firmemente podía conmover a la audiencia contra Hitler y sus matanzas. Pero el padre de los distingos entre pueblos puros e impuros y la imbatibilidad de la comunidad ética verdadera, el legislador que vence univocamente sobre las contingencias y el pluralismo de este mundo, aquel en quien la obediencia hacia un Fundamento Absoluto Invisible puede sin piedad sobre el propio hermano fulminado por su comunicatividad apasionada y su estética popular... ése queda como lo inescenificable. Aun para el sionista que acabó siendo Schönberg, hubiera sido radicalmente incómodo oponer a Hitler una figura en cierto modo tan llena de rasgos que el mismo dictador cumplía. ¿0 era Aarón quien cumplía mejor ese incómodo expediente?

La fuerza arrebatadoramente política que hemos aprendido a descubrir en el Moisés y Aarón de Arnold Schönberg descansa sobre una sospecha y una constatación. La sospecha de cuán inexcusables son para la cultura de la última modernidad las tensiones entre solipsismo y comunitarismo, entre dogmatismo y demagogia, entre el silencio y la magia, entre norma y fiesta, entre ley e ídolo. Y la constatación de hasta qué punto se pudrieron en la figura de Adolf Hitler las dos figuras que habian representado en la brillante Europa del pasado ambas tendencias: el legislador y el artista. 
1 Quizá interese la cronología de la composición, pues encierra el detalle del adiós a Alemania: en 1926, escribe el celebrado preludio a la obra Viaje al infierno. En 1930 concluye la primera parte: Las historias de Jacob [publicada en Berlín en 1933]. En 1932 concluye la segunda: El joven José [editada en Berlín en 1934]. En julio de 1936 termina de escribir la tercera: José en Egipto [que apareció en Viena a fines de ese mismo año]. Y el 4 de enero de 1943 puso punto final al cuarto volumen: José, el proveedor [que apareció en Estocolmo].

2 Para un estudio exhaustivo de las fuentes empleadas por Mann en La Ley, a partir de documentos de primera mano por vez primera "revelados" por la investigación crítica, vid. el imprescindible trabajo de Klaus Machoschey (Machoschey, 1998). Para las notas del escritor sobre las circunstancias históricas y el plan de composición de $L a$ Ley, léase el trabajo de Hans Wysling (Wysling, 1979).

$3 Y$ aunque sus premisas distan ciertamente de las que he adoptado en este texto, las palabras de Karl-Josef Kuschel en un ensayo titulado La ética mundial y las experiencias de los escritores. La búsqueda de Thomas Mann de una "Ley Fundamental de la decencia humana" (Küng; Kuschel, 2006, 401-433) dan una idea muy oportuna de cómo sigue leyéndose el texto manniano: "Así, la narración de Thomas Mann La Ley podría leerse como expresión de la permanente fragmentación de la conciencia moderna. Se afirma en última instancia la moral, pero sólo al precio del distanciamiento irónico, puesto que se conocen las ambivalentes condiciones de su surgimiento. Al mismo tiempo se hace tanto más necesaria la afirmación de una ética universalmente vinculante cuanto más se sabe de la permanente amenaza a que está sometida y de su posible carácter ilusorio. Pero todo esto no es ninguna coartada para el relativismo moral. El análisis de las condiciones de su origen no debe estar en manos de quienes intentan 'sacudirse' la moral o 'rechazarla'. Quien con espíritu volteriano, contribuye a exponer la ley moral no forma parte de aquellos que la niegan. Es alguien que elige una tercera vía, entre el moralismo acrítico y el nihilismo cínico" (Küng; Kuschel, 2006, 426-427).

4 Hemos de tomar conciencia aún hoy del impacto político-social del nuevo lenguaje a partir de la segunda década del siglo XX. Quizás la crónica de una velada tan tristemente memorable como la del 31 de marzo de 1913 en Viena, nos ayude un poco. El musicólogo Henry-Louis de La Grange es un cicerone ideal para relatar cómo discurrió aquel concierto organizado por la Akademischer Verband fúr Literatur und Musik, en que los músicos intentaron defender un programa montado por Schönberg, que incluia las seis Piezas para orquesta de Webern, los Maeterlinck Lieder de Zemlinsky, la Kammersymphonie op. 9 del propio compositor y dos de los Altenberg-Lieder de Berg. Los Kindertotenlieder de Mahler cerraban, eso decía el cartel, el concierto. "Son los Lieder de Berg los que disparan la agitación hasta el límite, pues el vasto efectivo orquestal utilizado para dos piezas tan breves causa el efecto de una nueva provocación. El tenor Alfred Boruttau se detiene para apelar a la calma y el presidente de la Asociación aparece con nuevas amenazas de evacuación de los manifes- 
tantes. La palabra Hinaus ('iFuera!'), que canta Alfred Boruttau con un do sobreagudo, desencadena entonces un alboroto indescriptible, aullidos, gritos de animales, intercambios de injurias e incluso de golpes, de manera que esta vez el concierto queda definitivamente interrumpido. En su palco, el dulce Webern se levanta para insultar en voz alta a los boicoteadores. Le contestan que los partidarios de la nueva estética merecen ni más ni menos que les internen. La intervención de un comisario de policía de uniforme no logra que cese el tumulto. Finalmente, el presidente de la Asociación reaparece en escena y solicita que, por respeto a la memoria de Mahler, se restablezca la calma para la ejecución de los Kindertotenlieder. Pero las cosas han ido ya demasiado lejos. Una nueva injuria que se pronuncia desde la platea exaspera hasta tal punto al honorable presidente que salta desde el estrado, escala una hilera de butacas y propina al grosero (de hecho un médico respetable a quien esta música saca de sus casillas) una sonora bofetada. La sala se pone entonces a insultar a los músicos que, aterrorizados, huyen. El asunto termina ante los tribunales, pues varios de los manifestantes han sido multados. El compositor Oscar Strauss, al que llaman a testimoniar, reconoce haber oído la bofetada, que le ha parecido "el momento más sonoro del concierto" (De La Grange, 2002, 315-316).

\section{BIBLIOGRAFÍA}

Assmann, Jan (2006): La distinción mosaica. $\mathrm{O}$ el precio del monoteísmo, Madrid, Akal.

Benjamin, Walter (1977): Gesammelte Schriften. Band II, 1. Aufsätze, Essays, Vorträge, Frankfurt am Main, Suhrkamp.

Cacciari, Massimo (2002): Icone della legge, Milán, Adelphi.

Casals, Josep (2003): Afinidades vienesas. Sujeto, lenguaje, arte, Barcelona, Anagrama.

De La Grange, Henry-Louis (2002): Viena, una historia musical, Barcelona, Paidós.

Derrida, Jacques (2008²): Fuerza de ley. El "fundamento mistico de la autoridad", Madrid, Tecnos.

Freud, Sigmund (1981): Moisés y la religión monoteista y otros escritos sobre judaísmo y antisemitismo, Madrid, Alianza.

Godelier, Maurice (1998): El enigma del don, Barcelona, Paidós.
Küng, Hans; Kuschel, Karl-Josef, eds. (2006): Ciencia y ética mundial, Madrid, Trotta.

Mann, Thomas (1990): Erzählungen. Gesammelte Werke in dreizehn Bänden. Band VIII, Frankfurt am Main, Fischer Taschenbuch Verlag.

- (1973): La muerte en Venecia. Las tablas de la ley, Barcelona, Planeta.

- (2004): Oíd, alemanes... Discursos radiofónicos contra Hitler, Barcelona, Peninsula.

Makoschey, Klaus (1998): Quellenkritische Untersuchungen zum Spätwerk Thomas Manns, en Thomas-Mann-Studien, siebzehnter Band, Frankfurt am Main, Vittorio Klostermann.

Ouaknin, Marc-Alain (1999): El libro quemado. Filosofía del Talmud, Madrid, Riopiedras ediciones.

Pérez, Ana, ed. (2008): El exilio alemán (1933-1945). Textos literarios y políticos, Madrid, Marcial Pons.

Pons, Jordi (2006): Arnold Schönberg. Ética, estética, religión, Barcelona, Acantilado.

Sloterdijk, Peter (1989): Crítica de la razón cínica, II, Madrid, Taurus.

Wysling, Hans (1979): Dichter und ihre Dichtugen: Thomas Mann, Teil II, 19181943, Bd 14/II, Frankfurt am Main, Heimeran/S. Fischer. 